\title{
Percepção da avaliação: um retrato da gestão pública em uma instituição de ensino superior (IES)*
}

\author{
Jonas Cardona Venturini** \\ Breno Augusto Diniz Pereira*** \\ Ronaldo Morales**** \\ Carolina Freddo Fleck***** \\ Zeno Batistella Junior****** \\ Mateus de Brito Nagel*******
}

SumÁrio: 1. Introdução; 2. Fundamentação teórica; 3. Método do trabalho; 4. Apresentação e discussão dos resultados; 5 . Considerações finais.

Summary: 1 . Introduction; 2. Theoretical framework; 3. Methodology; 4. Results and discussion; 5. Final remarks.

Palavras-chave: gestão pública; avaliação institucional; instituições de ensino superior.

KEY WORDs: public management; institutional evaluation; higher education institutions.

A avaliação das universidades vem sendo defendida como instrumento necessário para elevar a qualificação institucional, promovendo a melhoria do ensino, da pes-

\footnotetext{
* Artigo recebido em fev. 2008 e aceito em mar. 2009.

** Doutorando em administração pela Universidade Federal do Rio Grande do Sul (UFRGS). Email: jonasventurini@yahoo.com.br.

**** Doutor em administração pela Universidade Federal de Santa Maria (UFSM). Professor do Departamento de Ciências Administrativas da UFSM e do mestrado em administração da UFSM. Endereço: Rua Marechal Floriano Peixoto, 1184 - Centro - CEP 97015-372, Santa Maria, RS, Brasil. E-mail: brenodiniz@brturbo.com.br.

***:* Mestre em administração. Professor do Departamento de Ciências Administrativas da UFSM. Endereço: Rua Marechal Floriano Peixoto, 1184 - Centro — CEP 97015-372, Santa Maria, RS, Brasil.E-mail: morales@ccsh.ufsm.br.

$* * * * *$ Doutoranda em administração pela UFRGS, mestre em administração pela UFSM. E-mail: carolina.fleck@gmail.com.

****** Graduando em administração pela UFSM. E-mail: zenotapera@yahoo.com.br.

$* * * * * * *$ Graduando em administração pela UFSM. E-mail: mateus_nagel@yahoo.com.br.
} 
quisa, da extensão e de sua gestão. Com o objetivo de avaliar o processo de gestão institucional da Universidade Federal de Santa Maria (UFSM), no Rio Grande do Sul, este artigo apresenta os resultados de uma pesquisa que levantou os fatores que, na percepção de 163 docentes da UFSM, interferem na continuidade e no aperfeiçoamento do processo de avaliação institucional. Os dados foram coletados por meio de questionários e analisados através de técnicas estatísticas descritivas e inferenciais. Entre 79,9\% e 95,7\% dos fatores estudados facilitam ou dificultam o processo de avaliação, destacando-se com mais de $70 \%$ os seguintes: "consciência da importância da avaliação", "definição clara dos critérios indicadores a serem utilizados na avaliação", "definição e divulgação das políticas da instituição" e a "existência de comissão interna de avaliação". Em síntese, apesar do caráter exploratório do estudo, os resultados obtidos permitiram construir uma imagem adequada sobre a avaliação na UFSM.

\section{Evaluation perception: a portrait of public management in a higher education institution}

University evaluation has been defended as a necessary tool to promote institutional competence and to improve teaching, research, extension programs and institutional management. In order to examine the institutional management process at the Federal University of Santa Maria (Universidade Federal de Santa Maria, UFSM, in the state of Rio Grande do Sul, Brazil), this article presents the results of a research that identified the factors that, as perceived by 263 UFSM professors, interfere in the continuity and improvement of the institutional evaluation process. Data was collected in questionnaires and analyzed using descriptive and inferential statistical techniques. Between $79.9 \%$ and $95.7 \%$ of the studied factors either facilitate or obstruct the evaluation process, the following standing out with over 70\%: "being conscious of the importance of evaluation"; "clear establishment of the indicating criteria that will be used in the evaluation"; "establishment and disclosure of the institution's policies"; and the "existence of an internal evaluation commission". To summarize, despite the exploratory nature of the study, the results revealed an adequate picture of UFSM's evaluation process.

\section{Introdução}

A universidade pública, em nosso país, tem experimentado profundos questionamentos sobre a qualidade de suas atividades e a maneira como tem empregado os recursos que a sociedade coloca à sua disposição. A avaliação das universidades vem sendo defendida como instrumento necessário para elevar a qualificação institucional, promovendo a melhoria do ensino, da pesquisa, da extensão e de sua gestão. Também vem sendo entendida como exigência da sociedade, que quer saber dos recursos destinados às universidades as- 
sim como do desempenho alcançado com as ações desenvolvidas na busca de identificar as funções para as quais foram criadas.

Não há dúvida de que, cada vez mais, as universidades estão descobrindo seu caráter social e percebendo que precisam, urgentemente, conquistar, pela eficiência e qualidade, credibilidade e legitimidade junto à comunidade em que estão inseridas.

Nisso reside o sentido e a razão fundamental da avaliação da universidade que objetiva assegurar a boa qualidade do seu ensino, da sua pesquisa, extensão e processo de gestão, assim como o pleno atendimento das legítimas necessidades e expectativas da sociedade. É importante destacar que a universidade que se conhece e reflete sobre si mesma toma o seu destino nas próprias mãos, não permitindo que a rotina ou políticas governamentais sejam fatores preponderantes na definição de suas prioridades.

Tal questionamento é reflexo da preocupação que as pessoas, a partir de uma nova postura, vêm tendo em relação aos órgãos públicos em geral, e, principalmente, ao setor educacional e às universidades. Nesse contexto, este artigo busca melhor conhecer e avaliar o processo de avaliação institucional da UFSM.

\section{Fundamentação teórica}

A ideia de avaliar as universidades não é nova. Ela sempre, formal ou informalmente, ocorreu. Segundo Neiva (1987), ela sempre apareceu no dia a dia da universidade, mesmo que de forma difusa, em relatórios a órgãos superiores, confecção de estatísticas e outras informações de competência e responsabilidade de órgãos da estrutura interna da universidade.

No entanto, é verdade que esses mecanismos não produziram resultados satisfatórios. Como consequência, os questionamentos sobre as universidades, sobre a qualidade do seu desempenho, tanto em termos do ensino quanto da pesquisa, da extensão e da sua gestão, provêm da comunidade científica e da sociedade.

Já faz algum tempo que interesses privados internos, junto com grandes interesses econômicos externos, pressionam o Estado e as universidades públicas, produzindo, junto à sociedade, sérias críticas quanto à ineficiência dessa universidade: os custos elevados das atividades desenvolvidas, o pouco retorno à sociedade dos recursos a ela destinados (Teixeira et al., 2005). Para essa finalidade, é necessário rever a política de alocação de recursos nas universidades públicas assim como a interferência maior desses grupos privados no dia a dia da universidade. 
Esse constrangimento, existente entre todos os que se preocupam com o desenvolvimento científico e tecnológico do país e que vivem o cotidiano das salas de aula e laboratórios nas universidades, requer uma firme tomada de posição, no sentido de salvar algo que foi construído com muito esforço, competência e sacrifício por toda a sociedade.

É preciso pensar uma nova universidade que, preservando suas qualidades institucionais, consiga responder, de forma mais efetiva, aos novos e crescentes desafios, tornando-se, assim, mais eficiente e transparente à sociedade. Ela deverá incorporar técnicas de gestão e metodologias pedagógicas capazes de absorver todo o potencial tecnológico disponível (Nunes e Ferraz, 2005).

A implementação das mudanças necessárias na busca da nova universidade requer a implantação de um processo permanente de avaliação da instituição, a partir do qual seja possível elaborar o diagnóstico institucional, tarefa que tem se mostrado bastante complexa no interior das instituições de ensino superior do país.

Tal situação pode ser explicada por alguns fatos entre os quais se destaca a falta de parâmetros pelos quais esse julgamento possa ser realizado. Não existe um conjunto de dados que possa ser tomado como a expressão da universidade em seus vários aspectos, e os dados disponíveis têm, em muitos casos, qualidade duvidosa e não permitem comparações na própria universidade ao longo do tempo, muito menos entre as instituições. Falta um projeto de educação com políticas e objetivos definidos que sirvam como referência para avaliar esses julgamentos e aceitá-los ou não, bem como tem faltado vontade própria para discutir e implementar a avaliação institucional.

\section{Fatores que afetam a avaliação institucional nas universidades}

A educação superior, na indissociabilidade do ensino, pesquisa e extensão, não tem, ultimamente, atendido a determinadas aspirações ou interesses e, por isso, tem sido criticada. Tal constatação torna evidente a necessidade de redefinir a função social e científica da universidade, a partir de um novo projeto político-pedagógico, articulado com as novas exigências resultantes da nova realidade socioeconômica existente hoje (Antonello e Dutra, 2005).

Nesse sentido, de acordo com Faraco (1991), é fundamental avaliar a instituição para se ter uma base de decisão, para escolher os projetos com os quais comprometer-se-á e para permitir a reformulação dos conceitos sobre ensino, pesquisa, extensão e eficiência administrativa. 
O exame dos objetivos e finalidades da avaliação, seus princípios e características, permite constatar que ela pode constituir-se em estratégia institucional para construir uma ligação efetiva com a realidade social, representando o compromisso de contribuir efetivamente na reconstrução de espaço social mais justo.

Portanto, implementar um processo de avaliação numa universidade acarretará transformações intensas, que poderão atingir todos os indivíduos que dela fazem parte, assim como todos os processos nela existentes.

Diante de tal constatação, a adequada implementação de um processo de avaliação requer a conscientização, por parte de seus promotores, de que existem alguns fatores que devem ser levados em consideração na medida em que podem interferir no processo, comprometendo sensivelmente os resultados desejados. Os dois principais fatores que afetam o processo de avaliação das instituições públicas são expostos a seguir.

\section{Reação às mudanças}

Dressel (1985) afirmou que, embora o processo de avaliação seja vantajoso para a organização universitária, quando promove flexibilidade e adaptabilidade, gera sérios conflitos em decorrência da presença do desejo de segurança e estabilidade. Segundo Durham (1988:35), "há docentes e pesquisadores inegavelmente competentes e responsáveis que parecem sentirem-se ameaçados por esse processo e que vêm se opondo sistematicamente a medidas desse tipo".

As universidades acalentam, no seu íntimo, a ideia de permanência, de imputabilidade, considerada pilar mestre para sua capacidade de possuir e infundir normas e valores. Por isso, quando o objetivo de eternidade é incorporado, o interesse pela inovação também é perdido, já que a ideia de imortalidade é oposta à de mudança, de risco, ou seja, ficam apegadas à sua tradição.

\section{Corporativismo}

A dimensão da arquitetura estrutural das universidades, associada ao seu elevado grau de especialização, transforma-se em fonte geradora de novas dimensões de poder, a partir de um complexo de relações funcionais que tornam o indivíduo incapaz de resolver, por si só, seus problemas pessoais. Para se fortalecer, naturalmente, procuram se unir como grupos funcionais. Não há 
como negar, o elevado grau de complexidade das organizações universitárias, ao mesmo tempo em que reforça, também cria novos limites para o desenvolvimento da iniciativa e da liberdade individual.

Para Nunes (1998:91):

O corporativismo, o elemento de solidariedade entre os docentes, pode representar grande aliado à resistência (...) A corporação dos funcionários técnicoadministrativos também pode ser reativa à avaliação, à medida que esta poderia identificar ociosidade e improdutividade de alguns setores.

Fortalecendo essa proposição, Almeida (1989:59) comentou que o corporativismo

dá corpo a uma forma por vezes vigorosa, mas sempre fragmentada de representação de interesses, com, pelo menos, dois efeitos possíveis (...) o primeiro faz prever um estilo de ação que poderá imprimir no perfil das instituições políticas sociais a marca do poder desigual dos interesses organizados, reproduzindo e confirmando desigualdades. O segundo efeito diz respeito à força conservadora que o modelo corporativista parece potencializar.

Diversos estudos evidenciam que a percepção de vantagens pessoais, obtidas por meio da participação, é o principal elo que liga o trabalhador aos esquemas participativos.

Assim, Messeder (1989:56) afirmou:

que a forma de participação significa ter o máximo de poder para recusar certas condições e certos tipos de trabalho, definir normas aceitáveis, controlar o respeito a essas normas pela hierarquia patronal secundariamente à percepção do poder.

Adiciona-se a essa constatação, outros fatores que também são geradores, estimuladores de novas pressões, tanto para a organização universidade, quanto para as pessoas que nela estão inseridas. Nesse particular, merece destaque o aumento das aspirações profissionais; a intensidade e a velocidade das mudanças observadas no ambiente, as quais têm atingido frontalmente a organização do trabalho, produzindo uma quebra de paradigma, sem precedentes, na sua forma tradicional de estruturar-se; e o grande desenvolvimento na tecnologia da informação, que tem contribuído, em muito, para o debate ideológico. 


\section{Método do trabalho}

O artigo procurou estudar o processo de avaliação institucional da UFSM, e os fatores intervenientes segundo a percepção de seus docentes. A partir da revisão, com base na literatura específica, elaborou-se uma série de considerações conceituais. Especificamente, os aspectos destacados na fundamentação teórica apresentada possibilitaram a elaboração e aplicação de uma metodologia que permitisse atingir o objetivo deste artigo.

A partir dos objetivos gerais, a pesquisa foi caracterizada como sendo do tipo descritiva. Segundo Marconi e Lakatos (1990) as pesquisas descritivas objetivam primordialmente descrever as características de determinada população.

A realização desta pesquisa implicou o estudo aprofundado de um fenômeno particular, efetivado em uma única organização: a UFSM. Nessa dimensão, caracteriza-se como um trabalho do tipo estudo de caso. Ainda de acordo com as autoras supracitadas, o estudo de caso caracteriza-se por ser um estudo profundo de poucos objetivos, de forma a permitir seu amplo e detalhado conhecimento.

O estudo limitou-se a buscar, num primeiro momento, conhecer a percepção dos docentes da UFSM sobre a avaliação institucional em implementação na instituição para, a seguir, partindo da percepção desses mesmos docentes, identificar os fatores que interferem na avaliação.

A população alvo da pesquisa foi constituída pelos docentes de nível superior, pertencentes ao quadro permanente de pessoal docente da UFSM, isto é, funcionários públicos federais. Portanto, não serão computados os professores substitutos e visitantes. Foram realizadas 163 entrevistas com os docentes da instituição.

A população pesquisada compreendeu os docentes pertencentes às categorias de professor auxiliar, assistente, adjunto e titular, com titulação de graduado, especialista, mestre e doutor, que estejam vinculados a um dos seguintes regimes de trabalho: $20 \mathrm{~h}$ semanais, $40 \mathrm{~h}$ semanais ou DE (dedicação exclusiva). A população pesquisada abrangeu os 1.101 professores da UFSM, conforme mapa do quadro docente, distribuídos pelos oito centros de ensino e nos 67 departamentos didáticos que fazem parte da estrutura da universidade.

Os dados utilizados no estudo são provenientes, basicamente, de fontes primárias e obtidos por meio de questionário respondido pelos docentes; também foram utilizados dados oriundos de fontes secundárias.

O questionário utilizado, elaborado a partir da revisão da literatura, com afirmativas sobre a avaliação institucional da UFSM e uma lista de fatores que normalmente interferem na avaliação, permite verificar e analisar 
a avaliação da UFSM e identificar os fatores que interferem nesse processo, seja dificultando ou facilitando, na percepção dos seus docentes. Para qualificar a coleta de dados, o questionário foi pré-testado em docentes lotados nos departamentos didáticos pertencentes ao Centro de Ciências Sociais e Humanas.

Além dos dados primários, foram utilizados dados secundários, obtidos por meio da análise dos seguintes documentos: Projeto de Avaliações da UFSM, Projeto Político-Pedagógico e relatórios elaborados pela Comissão Central de Avaliação.

Então, para coletar os dados da pesquisa, foi utilizado o método escalar desenvolvido por Likert, ou seja, solicitou-se, a cada docente entrevistado, a escolha da alternativa, entre as apresentadas, que melhor expressasse sua percepção em relação à avaliação da UFSM e sobre os fatores que nela interferem. Para tanto, o questionário foi estruturado com questões de escala tipo Likert.

O questionário utilizado foi dividido em três partes. A parte 1 buscou obter informações gerais do tipo: categoria do docente, titulação, regime de trabalho, centro de ensino de lotação, tempo de serviço e se ocupa ou já ocupou cargo de chefia na UFSM. A partir desses dados, foi possível fazer uma caracterização dos docentes pesquisados e identificá-los nas respostas dadas.

A parte 2 compreendeu 45 afirmativas sobre a avaliação da UFSM, para que os docentes expressassem sua percepção sobre cada uma delas. Isso permitiu identificar como está e qual a perspectiva do processo de avaliação em andamento na universidade.

\section{Apresentação e discussão dos resultados}

A UFSM tem sua sede na Cidade Universitária, no município de Santa Maria, Rio Grande do Sul, onde desenvolve a maior parte de suas atividades acadêmicas e administrativas. No centro da cidade, ainda há ainda alguns cursos, a sede administrativa de um centro de ensino e outras unidades de atendimento à comunidade. Em 2005, o Conselho Universitário aprovou a criação do Centro de Educação Superior Norte-RS/UFSM (Cesnors), passando a UFSM a contar com nove unidades universitárias.

A UFSM possui, hoje, em pleno desenvolvimento, cursos, programas e projetos nas mais diversas áreas do conhecimento humano. A instituição mantém 58 cursos de graduação presenciais, um curso de ensino a distância, e 53 cursos de pós-graduação permanentes, sendo 24 de mestrado, 12 de doutorado e 17 de especialização. Além destes, realiza cursos de especialização, de 
atualização, de aperfeiçoamento e de extensão em caráter eventual, atendendo diversificadas e urgentes solicitações de demanda regional.

O contingente educacional da UFSM é de 15.565 alunos em cursos permanentes, distribuídos entre os três níveis de ensino, dos quais 11.687 são do ensino de graduação, 1.885 do ensino de pós-graduação e 1.993 do ensino médio e tecnológico. O corpo docente é composto de 1.127 professores do quadro efetivo (graduação, pós-graduação e ensino médio e tecnológico) e 234 professores de contrato temporário; e o quadro de pessoal técnico-administrativo é composto por 2.546 servidores.

A estrutura administrativa da universidade compõe-se basicamente de três níveis: a administração superior, os centros de ensino e os departamentos didáticos. A administração superior é composta pelos órgãos deliberativos: Conselho Universitário, Conselho de Ensino, Pesquisa e Extensão e o de traçar as diretrizes da instituição e o Conselho de Curadores.

\section{Avaliação institucional da UFSM}

A criação do Programa de Avaliação Institucional das Universidades Brasileiras, em 1993, pelo Ministério da Educação, veio ao encontro dos propósitos da administração da UFSM, de continuar buscando a melhoria da qualidade dos serviços oferecidos pela instituição à sociedade, refletidas no trinômio ensino-pesquisa-extensão. A UFSM aderiu ao programa, em 1994, criando a Comissão de Apoio à Avaliação Institucional dos Cursos de Graduação.

Atualmente, está em vigência o Sistema de Avaliação da Educação Superior (Sinaes), instituído pela Lei no 10.861, de 14 de abril de 2004, que prevê a análise dos instrumentos de avaliação aplicados aos discentes, docentes e servidores da instituição, dentro das categorias relacionadas a seguir.

- Missão: identificar e avaliar as marcas que melhor caracterizam a instituição, definem sua identidade e indicam a responsabilidade social. Características principais do clima acadêmico e psicossocial da instituição.

v Corpo de professores/pesquisadores: descrever e qualificar esse conjunto de atores, com respeito à formação acadêmica e profissional, sua situação na carreira docente, programas/políticas de capacitação e desenvolvimento profissional, compromissos com o ensino, a pesquisa e a extensão, distribuição dos encargos, adesão aos princípios fundamentais da instituição, vincu- 
lação com a sociedade, concursos e outras formas de admissão na carreira docente.

- Corpo discente: descrever e qualificar o conjunto de estudantes, considerando importante a questão da integração de alunos e professores de distintos níveis e sua participação efetiva na vida universitária.

- Corpo de servidores técnico-administrativos: descrever e qualificar o conjunto dos servidores, considerando importante a questão da integração dos atores da comunidade universitária, servidores, alunos e professores.

- Currículos e programa: concepção de currículo, organização didático-pedagógica, objetivos, formação profissional e cidadã, adequação às demandas do mercado e da cidadania, integração do ensino com a pesquisa e a extensão, interdisciplinaridade, flexibilidade/rigidez curricular, extensão das carreiras, inovações didático-pedagógicas, utilização de novas tecnologias de ensino, relações entre graduação e pós-graduação.

- Produção acadêmico-científica: análise das publicações científicas, técnicas e artísticas, patentes, produção de teses, organização de eventos científicos, realização de intercâmbios e cooperação com outras instituições nacionais e internacionais, formação de grupos de pesquisa, interdisciplinaridade, política de investigação, relevância social e científica.

v Atividades de extensão e ações de intervenção social — vinculação com a sociedade: o valor educativo da extensão, sua integração com o ensino e a pesquisa, políticas de extensão e sua relação com a missão da universidade, transferências de conhecimento, importância social das ações universitárias, impactos das atividades científicas, técnicas e culturais para o desenvolvimento regional e nacional.

- Infraestrutura: análise da infraestrutura da instituição, em função das atividades acadêmicas de formação e de produção de conhecimentos.

- Gestão: avaliar a administração geral da instituição e de seus principais setores na perspectiva da globalidade.

- Outros: avaliar outros itens não mencionados e que sejam importantes para a instituição, como cursos não universitários, cursos a distância, hospitais, teatros, rádios e TVs, atividades artísticas, esportivas e culturais, mas sempre tendo em vista as finalidades essenciais e a missão da instituição. 


\section{Percepção dos docentes sobre a avaliação}

A partir das respostas que os docentes, componentes da amostra, deram às questões gerais, foi possível identificar algumas características do perfil dos docentes da UFSM.

$$
\text { Tabela } 1
$$

Percepção dos docentes em relação à metodologia utilizada na avaliação da UFSM

\begin{tabular}{|lcccccc|}
\hline \multirow{2}{*}{ Questões } & \multicolumn{5}{c}{ Respostas (\%) } & \multirow{2}{*}{ Total de } \\
\cline { 2 - 6 } & Ótimo & Bom & Regular & Ruim & Péssimo & respondentes \\
\hline Critérios de avaliação (29) & 0,6 & 44,8 & 40,5 & 5,5 & 3,7 & 163 \\
Indicadores utilizados (30) & 0,6 & 49,7 & 34,4 & 6,7 & 2,5 & 163 \\
Adequação ao projeto político- & 0,6 & 46,6 & 38 & 4,9 & 1,8 & 163 \\
pedagógico (31) & 1,2 & 36,2 & 39,9 & 9,2 & 2,5 & 163 \\
Indicadores/atendimento às & 0,6 & 45,4 & 36,2 & 9,8 & 3,1 & 163 \\
atividades (33) & 0 & 32,5 & 49,1 & 9,2 & 1,2 & \\
Compreensão/objetivos (34) & & & & & & \\
Instrumentos utilizados (37) & 0 & & & & & \\
\hline
\end{tabular}

Os resultados apresentados na tabela 1 evidenciam que na percepção da maioria dos docentes, mais de $80 \%$, os critérios e os indicadores utilizados na avaliação são bons ou regulares. Especificamente, 44,8\% e 40,5\% dos docentes entendem que os critérios utilizados são bons e regulares respectivamente, enquanto em relação aos indicadores $49,7 \%$ dizem que eles são bons, e 40,5\% dizem que são regulares (questões 29 e 30). Ressalta-se, ainda, o fato de $46,6 \%$ dos docentes perceberem que os indicadores escolhidos para avaliar a universidade atendem às suas diferentes atividades, num nível considerado bom, enquanto $38 \%$ opinam ser apenas razoável (questão 31).

Outra preocupação foi com os instrumentos utilizados para coletar os dados utilizados na avaliação. Na percepção de $45,4 \%$ dos docentes, eles são considerados bons e, para 36,2\%, são regulares (questão 37). A adequação do processo de avaliação ao projeto político-pedagógico da universidade foi considerada boa por $36,2 \%$ dos docentes e regular por $39,9 \%$.

Em relação ao tempo em que o professor está exercendo suas atividades na universidade, a maioria $(55,8 \%)$ está há mais de 10 anos na instituição, com destaque para o fato de que $28,2 \%$ deles estão há mais de 20 anos, e $41,1 \%$ estão na instituição há menos de 10 anos, destacando-se que $27 \%$ de- 
les estão a mais de cinco anos e menos de 10 anos. Os dados seriam alterados substancialmente não fosse o represamento, por parte do governo, da reposição dos docentes aposentados. A universidade conta hoje com a colaboração de mais ou menos 160 professores substitutos.

De qualquer forma, é lícito supor que a maioria dos professores, estando vinculados à UFSM há mais de 10 anos, conhecem sua estrutura, sua cultura, seus objetivos e sua missão.

\section{Estratégia de avaliação da UFSM}

Neste grupo, foram reunidas as questões que tratam das estratégias utilizadas para implementar o processo de avaliação na UFSM. Na tabela 2, estão os dados sobre a percepção dos docentes em relação às questões formuladas.

Tabela 2

Percepção dos docentes em relação à estratégia utilizada para implantar a avaliação da UFSM

\begin{tabular}{|c|c|c|c|c|c|c|c|}
\hline \multirow[b]{2}{*}{ Questões } & \multicolumn{6}{|c|}{ Respostas (\%) } & \multirow{2}{*}{$\begin{array}{c}\text { Total de } \\
\text { respondentes }\end{array}$} \\
\hline & Ótimo & Bom & Regular & Ruim & Péssimo & $\begin{array}{c}\text { Não } \\
\text { responderam }\end{array}$ & \\
\hline Atitude/avaliação (1) & 60,1 & 33,1 & 3,1 & 0,6 & 0 & 3,1 & 163 \\
\hline Mecanismos/atitude (2) & 40,5 & 40,5 & 11,7 & 3,1 & 0,6 & 3,7 & 163 \\
\hline $\begin{array}{l}\text { Assegurar participação da } \\
\text { comunidade ( } 3 \text { ) }\end{array}$ & 66,3 & 28,8 & 1,8 & 0 & 0 & 3,1 & 163 \\
\hline $\begin{array}{l}\text { Avaliação/instrumento de } \\
\text { controle (4) }\end{array}$ & 30,7 & 51,5 & 12,3 & 1,8 & 0,6 & 3,1 & 163 \\
\hline $\begin{array}{l}\text { Avaliação aluno/docente } \\
\text { (22) }\end{array}$ & 31,3 & 36,2 & 19,6 & 4,9 & 4,3 & 3,7 & 163 \\
\hline $\begin{array}{l}\text { Estratégia de implantação } \\
\text { (23) }\end{array}$ & 4,3 & 53,4 & 28,2 & 6,1 & 0,6 & 7,4 & 163 \\
\hline $\begin{array}{l}\text { Avaliação/importância } \\
\text { geral (42) }\end{array}$ & 35 & 42,3 & 14,7 & 2,5 & 1,2 & 4,3 & 163 \\
\hline Total & 100 & 100 & 100 & 100 & 100 & 100 & \\
\hline
\end{tabular}

A análise desses dados possibilita conclusões importantes. A primeira é que a realização sistemática na avaliação da universidade com a finalidade de acompanhar seu desempenho (questão 1), na percepção de 93,2\% dos docentes é ótima para $60,1 \%$, e boa para $33,1 \%$. Tal posição fica fortalecida quando 
se observa que na percepção de $82,2 \%$ e $77,3 \%$ dos docentes (questões 4 e 42) é ótimo e bom a avaliação servir como instrumento adequado para diagnosticar situações a serem corrigidas, redirecionar ações, indicar prioridades e efetuar o controle, caracterizando-se, assim, como importante instrumento de gestão.

Criar mecanismos que assegurem a participação da comunidade externa (bom, para 40,5\%; ótimo, para 40,5\%) e assegurar a participação da comunidade interna, docentes, funcionários e alunos (bom, para 28,8\%; ótimo, para 66,3\%) afiguram-se como estratégias corretas na avaliação da UFSM segundo a percepção dos docentes da UFSM (questões 2 e 3). Os docentes, quase na sua totalidade, concordam com a estratégia de submeter a universidade a uma avaliação interna e externa. Em termos de avaliação interna (questão 22), para a grande maioria dos docentes $(67,5 \%)$ a estratégia de incluir no processo de avaliação da universidade a avaliação dos docentes pelos discentes é ótima e boa.

Por fim, numa síntese das questões, pode-se afirmar que, de acordo com a percepção dos docentes, há concordância com a estratégia adotada para implantar a avaliação institucional na universidade, pois foi considerada regular para $28,2 \%$, boa para $53,4 \%$ e ótima para $4,3 \%$ dos docentes (questão 23 ).

\section{Processo de comunicação utilizado para implementar a avaliação da UFSM}

Neste particular, buscou-se identificar o nível de conhecimento e compreensão da comunidade em relação à avaliação institucional e aos aspectos fundamentais na sua implementação, com o intuito de avaliar o processo de comunicação utilizado. Os resultados obtidos encontram-se na tabela 3.

Tabela 3

Percepção dos docentes em relação ao processo de comunicação na implantação da avaliação da UFSM

\begin{tabular}{|lccccccc|}
\hline & \multicolumn{8}{c|}{ Respostas (\%) } & Total de \\
\cline { 2 - 7 } & Ótimo & Bom & Regular & Ruim & Péssimo & $\begin{array}{c}\text { Não } \\
\text { responderam }\end{array}$ & 163 \\
\hline $\begin{array}{l}\text { Conhecimento/ } \\
\text { compreensão (10) }\end{array}$ & 0 & 11,7 & 62,2 & 18,4 & 3,7 & 3,7 & 163 \\
$\begin{array}{l}\text { Processo de } \\
\text { comunicação (27) }\end{array}$ & 0 & 27 & 51,5 & 12,9 & 3,1 & 5,5 & \\
\hline
\end{tabular}




\begin{tabular}{|c|c|c|c|c|c|c|c|}
\hline \multirow[b]{2}{*}{ Questões } & \multicolumn{6}{|c|}{ Respostas (\%) } & \multirow{2}{*}{$\begin{array}{l}\text { Total de } \\
\text { respondentes }\end{array}$} \\
\hline & Ótimo & Bom & Regular & Ruim & Péssimo & $\begin{array}{c}\text { Não } \\
\text { responderam }\end{array}$ & \\
\hline $\begin{array}{l}\text { Conhecimento } \\
\text { da comunidade } \\
\text { universitária (28) }\end{array}$ & 0 & 15,3 & 48,5 & 25,2 & 7,4 & 3,7 & 163 \\
\hline $\begin{array}{l}\text { Conhecimento } \\
\text { projeto político- } \\
\text { pedagógico (32) }\end{array}$ & 0 & 19 & 60,7 & 13,5 & 2,5 & 4,3 & 163 \\
\hline $\begin{array}{l}\text { Compreensão do } \\
\text { objetivo da avaliação } \\
\text { (34) }\end{array}$ & 0 & 16,7 & 54,4 & 20 & 4,7 & 4,3 & 163 \\
\hline Total & 100 & 100 & 100 & 100 & 100 & 100 & \\
\hline
\end{tabular}

Os resultados não deixam dúvida que, na percepção dos docentes, o processo de comunicação utilizado não atingiu seus objetivos. Isso é preocupante por dois aspectos fundamentais. Primeiro sabe-se que quanto menor for o nível de informação e conhecimento dos docentes sobre o processo de sua avaliação, menores são as chances de se obter sua participação e comprometimento. Pontos fundamentais para uma atividade a ser implementada pela adesão voluntária. Por outro lado, é óbvio que a continuidade do processo requer novos esforços e estratégias em seu processo de comunicação como condição para garantir sua efetividade.

Os resultados obtidos permitem concluir que, na percepção dos docentes, a liderança exercida pelas diversas chefias na implementação do processo de avaliação da UFSM está adequada. Isso quer dizer que os docentes aceitam as lideranças existentes e que as chefias têm conseguido influenciar e motivar os docentes a participarem do processo.

\section{Participação/envolvimento/comprometimento com a avaliação da UFSM}

Este artigo identifica a percepção dos docentes sobre a atuação da comunidade universitária, egressos, dirigentes e conselhos na avaliação da UFSM. Os resultados encontram-se na tabela 4.

Os dados mostram que a participação dos egressos no processo de avaliação da UFSM é boa, segundo a percepção de $20,2 \%$ dos docentes, regular para $25,8 \%$, ruim para $31,9 \%$ e péssima para $10,4 \%$, que não pode ser considerada como satisfatória (questão 6). Aqui há de se considerar a dificuldade 
existente para manter contato com os ex-alunos em decorrência da inexistência de um banco de dados. Visando sanar essa deficiência, a reitoria criou um endereço eletrônico específico, com a finalidade de permitir que os ex-alunos se cadastrem e tenham um canal de comunicação constante com a instituição. Este é, sem dúvida, um aspecto que requer maior atenção dos responsáveis pelo processo.

Tabela 4

Percepção dos docentes em relação à participação e comprometimento da comunidade interna e externa com a avaliação da UFSM

\begin{tabular}{|c|c|c|c|c|c|c|c|}
\hline \multirow[b]{2}{*}{ Questões } & \multicolumn{6}{|c|}{ Respostas (\%) } & \multirow{2}{*}{$\begin{array}{l}\text { Total de } \\
\text { respondentes }\end{array}$} \\
\hline & Ótimo & Bom & Regular & Ruim & Péssimo & $\begin{array}{c}\text { Não } \\
\text { responderam }\end{array}$ & \\
\hline $\begin{array}{l}\text { Participação/ } \\
\text { comprometimento dos } \\
\text { dirigentes da UFSM (11) }\end{array}$ & 3,1 & 45,4 & 39,9 & 6,1 & 1,8 & 3,7 & 163 \\
\hline $\begin{array}{l}\text { Participação/ } \\
\text { comprometimento dos } \\
\text { dirigentes da comunidade } \\
\text { universitária (12) }\end{array}$ & 0 & 14,1 & 63,2 & 17,8 & 1,8 & 3,1 & 163 \\
\hline $\begin{array}{l}\text { Envolvimento/ } \\
\text { comprometimento do } \\
\text { conselho do centro (13) }\end{array}$ & 7,4 & 41,1 & 38 & 5,5 & 1,2 & 6,7 & 163 \\
\hline $\begin{array}{l}\text { Envolvimento/ } \\
\text { comprometimento dos } \\
\text { conselhos superiores (14) }\end{array}$ & 4,9 & 37,4 & 36,8 & 7,4 & 1,2 & 12,3 & 163 \\
\hline $\begin{array}{l}\text { Envolvimento/ } \\
\text { comprometimento do } \\
\text { conselho departamental (15) }\end{array}$ & 4,9 & 38 & 39,3 & 13,5 & 1,2 & 3,1 & 163 \\
\hline Participação dos egressos (16) & 0,6 & 20,2 & 25,8 & 31,9 & 10,4 & 11 & 163 \\
\hline $\begin{array}{l}\text { Esforço da comunidade } \\
\text { universitária (43) }\end{array}$ & 31,9 & 41,7 & 19 & 3,1 & 0,6 & 3,7 & 163 \\
\hline Total & 100 & 100 & 100 & 100 & 100 & 100 & \\
\hline
\end{tabular}

Finalizando esse ponto, questionaram-se os docentes sobre sua percepção quanto ao esforço que a comunidade universitária da UFSM está fazendo para construir um projeto de universidade comprometida com a qualidade do ensino, pesquisa e extensão (questão 43). A grande maioria é de percepção que o esforço efetuado é ótimo (31,9\%) e bom $(41,7 \%)$, o que de certa forma tem garantido a qualidade da instituição. 


\section{Implementação}

O objetivo deste tópico é conhecer a percepção dos docentes sobre a implementação do processo de avaliação da UFSM cujos resultados encontram-se na tabela 5 .

O trabalho de conscientização efetuado junto aos três segmentos da comunidade universitária, com a finalidade de informar sobre a avaliação institucional, sua importância e o significado de sua implementação foi considerado ótimo e bom por $30,1 \%$ dos docentes, $50,3 \%$, a maioria, opinou que ele apenas foi regular e $16,6 \%$ consideraram que ele foi ruim ou péssimo (questão 7 ).

$$
\text { Tabela } 5
$$

Percepção dos docentes em relação às ações desenvolvidas na implantação da avaliação da UFSM

\begin{tabular}{|c|c|c|c|c|c|c|c|}
\hline \multirow[b]{2}{*}{ Questões } & \multicolumn{6}{|c|}{ Respostas (\%) } & \multirow{2}{*}{$\begin{array}{c}\text { Total de } \\
\text { respondentes }\end{array}$} \\
\hline & Ótimo & Bom & Regular & Ruim & Péssimo & $\begin{array}{c}\text { Não } \\
\text { responderam }\end{array}$ & \\
\hline $\begin{array}{l}\text { Conscientização/ } \\
\text { informação sobre a } \\
\text { avaliação (7) }\end{array}$ & 4,9 & 25,2 & 50,3 & 12,3 & 4,3 & 3,1 & 163 \\
\hline $\begin{array}{l}\text { Ações de implementação } \\
\text { da avaliação (8) }\end{array}$ & 3,7 & 33,1 & 52,8 & 5,5 & 1,8 & 3,1 & 163 \\
\hline $\begin{array}{l}\text { Participação da } \\
\text { comunidade universitária } \\
\text { em eventos da avaliação } \\
\text { (9) }\end{array}$ & 2,5 & 11 & 57,5 & 20,9 & 4,3 & 3,7 & 163 \\
\hline $\begin{array}{l}\text { Qualificação técnica/ } \\
\text { Comissão Central de } \\
\text { Avaliação (18) }\end{array}$ & 12,3 & 55,2 & 14,7 & 4,9 & 1,2 & 11,7 & 163 \\
\hline $\begin{array}{l}\text { Vínculo da Comissão } \\
\text { Central de Avaliação com } \\
\text { o reitor (19) }\end{array}$ & 16,6 & 44,2 & 23,3 & 6,7 & 4,3 & 4,9 & 163 \\
\hline $\begin{array}{l}\text { Decisão favorável às } \\
\text { comissões de avaliação } \\
\text { por centro de ensino (20) }\end{array}$ & 30,1 & 54 & 9,8 & 1,8 & 0 & 4,3 & 163 \\
\hline $\begin{array}{l}\text { Composição das } \\
\text { comissões (21) }\end{array}$ & 10,4 & 54,6 & 17,8 & 3,1 & 0,6 & 13,5 & 163 \\
\hline Total & 100 & 100 & 100 & 100 & 100 & 100 & \\
\hline
\end{tabular}

As ações implementadas com a finalidade de efetivar o processo de avaliação obtiveram resposta mais positiva, pois foram consideradas ótimas ou 
boas por $36,8 \%$, regulares por $52,8 \%$ e ruins ou péssimas por $7,3 \%$ (questão 8). O mesmo não pode ser afirmado quando se analisa a percepção dos docentes em relação à participação da comunidade em palestras/encontros/seminários sobre avaliação institucional. A maioria dos docentes, 57,7\%, é de percepção que essa participação pode ser considerada razoável, 25,2\% têm percepção de que ela pode ser considerada ruim e péssima enquanto somente 13,5\% a considerou boa e ótima (questão 9).

As comissões de avaliação, tanto a central quanto as dos centros de ensino, obtiveram percepção favorável dos docentes. Especificamente a qualificação técnica da comissão central foi aprovada pela maioria dos docentes: $67,5 \%$ consideraram que ela é ótima ou boa, 14,7\% afirmam que ela é razoável e tão somente $6,1 \%$ entendem ser ela ruim ou péssima (questão 18). Quanto ao fato de ela estar vinculada ao gabinete do reitor foi considerado, por $60,8 \%$ dos docentes, uma decisão ótima ou boa, regular por $23,3 \%$, e ruim ou péssima por 11\% dos docentes (questão 19). Da mesma forma, a composição das duas comissões foi aprovada pelos docentes. A percepção preponderante, $65 \%$ dos docentes, é de que ela é ótima ou boa, e apenas 17,8\% dos que opinaram entenderam ser ela apenas razoável (questão 21).

O destaque fica por conta da ampla aprovação à decisão de que cada centro de ensino tenha sua própria comissão, $84,1 \%$ dos docentes consideraram ser esta uma decisão ótima ou boa (questão 20).

\section{Tratamento dos resultados}

Em qualquer processo de avaliação, sempre é alvo de atenção especial os resultados obtidos e o tratamento a eles dispensados. Por meio das questões 35 , 36 e 38, cujos dados encontram-se na tabela 6 , procurou-se saber, na percepção dos docentes, se os resultados obtidos atingiram os objetivos propostos pela avaliação, se ela tem contribuído para a melhoria de ensino, pesquisa e extensão, e se concordaram com a forma adotada para divulgá-los.

Quanto aos resultados obtidos na avaliação da UFSM terem atendido aos objetivos propostos foi bom para $35,6 \%$ dos docentes, para $48,5 \%$ foi apenas regular, e para 8,0\% ele foi ruim ou péssimo (questão 35). Já as contribuições da avaliação para o ensino, pesquisa e extensão foram, na percepção de $46 \%$ dos docentes, ótimas ou boas; regulares para $36,8 \%$; e ruins ou péssimas para $12,3 \%$ (questão 38 ). A forma adotada pela UFSM para divulgar os resultados da sua avaliação, na percepção dos docentes, foi considerada boa por 32,5\%, regular por $42,9 \%$ e ruim ou péssima por $19,1 \%$. 
Tabela 6

Percepção dos docentes em relação aos resultados da avaliação da UFSM

\begin{tabular}{|c|c|c|c|c|c|c|c|}
\hline \multirow[b]{2}{*}{ Questões } & \multicolumn{6}{|c|}{ Respostas (\%) } & \multirow{2}{*}{$\begin{array}{l}\text { Total de } \\
\text { respondentes }\end{array}$} \\
\hline & Ótimo & Bom & Regular & Ruim & Péssimo & $\begin{array}{c}\text { Não } \\
\text { responderam }\end{array}$ & \\
\hline $\begin{array}{l}\text { Resultados obtidos/ } \\
\text { objetivos propostos (35) }\end{array}$ & 0 & 35,6 & 48,5 & 5,5 & 2,5 & 8 & 163 \\
\hline $\begin{array}{l}\text { Divulgação dos resultados } \\
\text { (36) }\end{array}$ & 0 & 32,5 & 42,9 & 16,6 & 2,5 & 5,5 & 163 \\
\hline $\begin{array}{l}\text { Contribuiç̦ões da } \\
\text { avaliação (38) }\end{array}$ & 4,9 & 41,1 & 36,8 & 9,2 & 3,1 & 4,9 & 163 \\
\hline Total & 100 & 100 & 100 & 100 & 100 & 100 & \\
\hline
\end{tabular}

\section{Perspectivas futuras da avaliação institucional da UFSM}

Não basta implantar o processo de avaliação, é necessário conseguir que ele seja permanente e sistemático. Isso nos remete a outra questão básica no processo de avaliação da UFSM, suas perspectivas futuras. Procurando conhecer a percepção dos docentes nesse particular, foram formuladas sete questões, e os resultados obtidos encontram-se na tabela 7.

Tabela 7

Percepção dos docentes em relação às perspectivas futuras da avaliação da UFSM

\begin{tabular}{|c|c|c|c|c|c|c|c|}
\hline \multirow[b]{2}{*}{ Questões } & \multicolumn{6}{|c|}{ Respostas (\%) } & \multirow{2}{*}{$\begin{array}{l}\text { Total de } \\
\text { respondentes }\end{array}$} \\
\hline & Ótimo & Bom & Regular & Ruim & Péssimo & $\begin{array}{c}\text { Não } \\
\text { responderam }\end{array}$ & \\
\hline $\begin{array}{l}\text { Conhecimento sobre a } \\
\text { missão da UFSM (5) }\end{array}$ & 4,3 & 39,9 & 46,6 & 4,9 & 0,6 & 3,7 & 163 \\
\hline $\begin{array}{l}\text { Conhecimento sobre } \\
\text { missão e objetivos (6) }\end{array}$ & 1,2 & 36,2 & 50,9 & 7,4 & 1,2 & 3,1 & 163 \\
\hline $\begin{array}{l}\text { Qualificação técnica da } \\
\text { comissão central (17) }\end{array}$ & 0,6 & 20,9 & 55,8 & 13,5 & 4,3 & 4,9 & 163 \\
\hline $\begin{array}{l}\text { Contribuições futuras } \\
\text { para melhoria do } \\
\text { processo didático- } \\
\text { pedagógico (39) }\end{array}$ & 17,2 & 55,2 & 19 & 3,1 & 0,6 & 4,9 & 163 \\
\hline
\end{tabular}

Continua 


\begin{tabular}{|c|c|c|c|c|c|c|c|}
\hline \multirow[b]{2}{*}{ Questões } & \multicolumn{6}{|c|}{ Respostas (\%) } & \multirow{2}{*}{$\begin{array}{c}\text { Total de } \\
\text { respondentes }\end{array}$} \\
\hline & Ótimo & Bom & Regular & Ruim & Péssimo & $\begin{array}{c}\text { Não } \\
\text { responderam }\end{array}$ & \\
\hline $\begin{array}{l}\text { Contribuições futuras } \\
\text { para ensino/pesquisa/ } \\
\text { extensão (40) }\end{array}$ & 22,1 & 55,2 & 14,7 & 2,5 & 1,2 & 4,3 & 163 \\
\hline $\begin{array}{l}\text { Perspectivas futuras } \\
\text { (44) }\end{array}$ & 9,2 & 61,3 & 20,9 & 3,1 & 0,6 & 4,9 & 163 \\
\hline $\begin{array}{l}\text { Comprometimento } \\
\text { com os objetivos da } \\
\text { UFSM (45) }\end{array}$ & 1,8 & 45,4 & 42,9 & 3,7 & 1,2 & 4,9 & 163 \\
\hline Total & 100 & 100 & 100 & 100 & 100 & 100 & \\
\hline
\end{tabular}

A preocupação inicial foi com o nível de confiança que a comunidade universitária tem em relação ao processo de avaliação da UFSM (questão 17). Na percepção de $21,5 \%$ dos docentes, ele é ótimo ou bom; a maioria, 55,8\%, entende que o nível de confiança é apenas regular; e 17,8\% entendem ser ele ruim ou péssimo. Os resultados evidenciam que o nível de confiança no processo não pode ser considerado satisfatório e pode comprometer seu futuro.

Duas questões foram abordadas na sequência, com a finalidade de conhecer a percepção dos docentes em relação às contribuições futuras que a avaliação pode trazer para o processo didático-pedagógico, da universidade e para qualificar o ensino, a pesquisa e a extensão por ela desenvolvidas. Em relação ao processo didático-pedagógico a percepção de $72,4 \%$ é de que são ótimas ou boas as contribuições que a avaliação pode trazer, para 19\% elas são razoáveis e para 3,7\% são ruins ou péssimas (questão 39). Quanto às possibilidades da avaliação contribuir, no futuro, para qualificar o ensino, pesquisa e extensão, a maioria dos docentes, 77,3\%, entende que elas são ótimas ou boas, $14,7 \%$ que elas são regulares, e apenas 3,7\% que elas são ruins ou péssimas (questão 40).

Outros dois fatores estão relacionados com as perspectivas futuras, não só do processo de avaliação como da própria universidade: a missão docente e a missão e objetivos da UFSM. Formularam-se, então, duas questões com o intuito de conhecer a percepção dos docentes sobre o nível de conhecimento que eles têm sobre sua missão (questão 5). Os resultados evidenciam que na percepção de $44,2 \%$ dos docentes da UFSM estes têm um nível de conhecimento ótimo ou bom sobre sua própria missão de docentes, $46,6 \%$ entendem que esse nível de conhecimento é apenas regular e 5,5\% opinam ser ele ruim ou péssimo. Já a percepção dos docentes em relação ao nível de conhecimento que eles têm sobre a missão e os objetivos da UFSM 
mostra que para $37,4 \%$ esse nível de conhecimento é ótimo ou bom, 50,9\% opinam que tal conhecimento é razoável e para $8,6 \%$ tal conhecimento é ruim ou péssimo (questão 6).

A seguir, questionaram-se os docentes buscando identificar sua percepção em relação ao comprometimento deles com os objetivos da universidade (questão 45). Na percepção de 47,2\% dos docentes, o comprometimento é considerado ótimo e bom; para 42,9, regular; e para 4,9\%, ruim e péssimo.

As opiniões com relação à própria missão docente e à missão da instituição chamam a atenção quando se considera o fato de que a grande maioria, mais de $80 \%$ dos docentes, exercem suas atividades há mais de cinco anos na UFSM. Em relação à missão docente, fica evidente a necessidade urgente da criação de um programa de treinamento para os docentes que ingressam e para os que já estão na universidade. É preciso considerar que a maioria não é oriunda de licenciatura.

Em relação à missão da UFSM, mais uma evidência da necessidade de programa de recepção aos novos docentes e de ações que permitam aos atuais docentes conhecer a missão, princípios e objetivos da instituição. Tais ações certamente contribuirão também para melhorar o comprometimento dos docentes com a instituição e, por consequência, com o seu processo de avaliação.

Finalizando, perguntou-se aos docentes sua percepção, considerando todas as questões anteriormente abordadas, sobre quais seriam as perspectivas futuras da avaliação da UFSM. A expressiva maioria (70,5\%) percebe que elas são ótimas ou boas, $20,9 \%$ que são razoáveis e para 3,7\% elas são ruins e péssimas.

\section{Considerações finais}

Os resultados da pesquisa permitem afirmar que, na percepção da maioria dos docentes, o processo de avaliação institucional em andamento na UFSM é considerado como bom ou regular. Dessa forma, dentro de um contexto de maior preocupação com o profissionalismo da gestão pública, pode-se dizer que a UFSM encontra-se em um bom caminho.

Entretanto, vale ressaltar as dificuldades em relação aos fatores que interferem na gestão, e que dificultam o processo de avaliação, na percepção de mais de $90 \%$ dos docentes, destacando-se a descrença quanto à utilização dos resultados, a dificuldade para mensurar os objetivos, a falta de incentivo à efi- 
ciência, a falta de indicadores precisos para medir a produtividade, a falta de transparência administrativa e a falta de vontade política para implementar a avaliação.

Pode-se citar ainda a dificuldade para mensurar objetivos, incentivar a eficácia e medir a produtividade, apesar de esforços para a implementação de planejamento estratégico, realizada formalmente, mas com dificuldades operacionais, principalmente, por características inerentes a uma organização pública.

Além disso, a falta de vontade política para implementar a avaliação percebida pelos docentes decorre, apesar dos esforços efetuados e da criação de comissões específicas, da inexistência de uma agenda condensada para que a implantação ocorra, envolvendo a reitoria, pró-reitores e direções de centro. Esse fato associa-se, sem dúvida alguma, ao que tem gerado grandes discussões no interior da universidade: o que fazer com os resultados obtidos na avaliação, problema crucial em qualquer processo de avaliação institucional.

Por último, buscava-se identificar as perspectivas do processo de avaliação na UFSM. Constata-se um alto grau de confiança no processo de avaliação e a crença generalizada de que a avaliação pode trazer importantes contribuições para o processo didático-pedagógico da instituição, que resultarão na qualificação do ensino, pesquisa, extensão e do seu processo de gestão. Para mais de $70 \%$ dos docentes, são ótimas ou boas as perspectivas futuras da avaliação institucional em implementação na UFSM.

Em síntese, considera-se que os resultados obtidos permitiram construir uma imagem adequada sobre a avaliação da UFSM, dos fatores que nela interferem e de suas perspectivas futuras seguindo percepção dos docentes. Acredita-se também que os dados obtidos possam ser importantes subsídios e contribuam para o processo de avaliação institucional da UFSM.

Considerando os objetivos deste artigo, os resultados obtidos e as conclusões apresentadas, recomenda-se:

v a realização de estudo similar junto ao segmento dos técnicos administrativos e dos alunos para se ter a percepção de toda a comunidade universitária;

v a implementação de outros estudos, de natureza qualitativa, visando à consolidação do processo de avaliação institucional;

v rigor na execução do planejamento estratégico, atrelando os objetivos às lacunas constatadas na avaliação institucional e fazendo cumprir metas e objetivos traçados, contornando os problemas inerentes às organizações públicas. 
Além do desenvolvimento de ações nos diversos níveis de poder da instituição com o intuito de fixar a avaliação como prioridade na UFSM e assegurar sua plena implementação e consolidação. Sem desconsiderar a importância da busca da eficácia administrativa e da indispensável qualidade do ensino, pesquisa e extensão desenvolvidos pela UFSM, recomenda-se que a premissa básica da avaliação institucional seja a de que, antes de tudo, ela é um processo educativo.

Por fim, cabe destacar que este artigo não é conclusivo, mas sim uma ampliação da discussão do tema que já foi debatida por autores como Leitão (1987), que explora a temática de indicadores de desempenho na universidade; e do trabalho de Motta (1981), que aborda a questão da participação na teoria gerencial aplicado a uma instituição pública. Uma avaliação de uma maneira teórico-empírica e num contexto peculiar.

\section{Referências}

ALMEIDA, M. H. T. Direitos sociais, organização de interesses e corporativismo no Brasil. Novos Estudos Cebrap, São Paulo, n. 25, p. 50-60, 1989.

ANTONELLO, C. S.; DUTRA, M. L. S. Projeto pedagógico: uma proposta para o desenvolvimento das competências de alunos do curso de administração com foco no empreendedorismo. In: ENCONTRO ANUAL DA ANPAD, 29. Anais... Brasília, 2005.

DRESSEL, P. L. Handbook of academic evolution. San Francisco: Jossey-Bass, 1985.

DURHAM, E. Avaliação na universidade: poder e democracia. Estudos e Debates, Brasília, n. 14, p. 75-79, 1988.

FARACO, C. A. Avaliação e gestão universitária. Curitiba: APUFPR, 1991. (Caderno 2: Avaliação na UFPR).

LEITÃO, S. P. Indicadores de desempenho na universidade: uma avaliação. RAP, Rio de Janeiro, v. 21, n. 2, p. 55-72, 1987.

MARCONI, M. A.; LAKATOS, E. M. Técnicas de pesquisa: planejamento e execução de pesquisa, amostragem e técnicas de pesquisa, elaboração, análise e interpretação de dados. 2. ed. São Paulo: Atlas, 1990.

MESSEDER, I. E. Recursos humanos e transformação social: onde se encontram os desafios? RAP, Rio de Janeiro, v. 23, n. 4, p. 49-61, 1989. 
MOTTA, P. R. A proposta de participação na teoria gerencial. RAP, Rio de Janeiro, v. 15, n. 3, p. 54-76, 1981.

NEIVA, C. Avaliação institucional. Brasília: Dois Pontos, 1987. p. 4.

NUNES, R. S. Administração universitária: concepções, modelos e estratégias gerenciais. 1998. Tese (Doutorado) — Faculdade de Economia, Administração e Contabilidade, Universidade de São Paulo, São Paulo.

NUNES, S. C.; FERRAZ, H. M. A reforma do ensino no Brasil e a inserção da noção de competências: um estudo empírico em instituições de educação superior. In: ENCONTRO ANUAL DA ANPAD, 29. Anais... Brasília, 2005.

TEIXEIRA, G. P. et al. A mercantilização do ensino superior brasileiro. In: ENCONTRO DE ESTUDOS ORGANIZACIONAIS, 4. Anais... Porto Alegre, 2006.

UFSM. Avaliação institucional. Universidade Federal de Santa Maria. Brasil, 2006. Disponível em: <www.ufsm.br>. Acesso em: 29 jul. 2006. 